Fixed Point Theory, 23(2022), No. 1, 75-84

DOI: $10.24193 /$ fpt-ro.2022.1.05

http://www.math.ubbcluj.ro/ nodeacj/sfptcj.html

\title{
ON ASYMPTOTICALLY NONEXPANSIVE MAPPINGS WITH NON-CONVEX DOMAINS
}

\author{
MONTHER RASHED ALFURAIDAN*, MOHAMED AMINE KHAMSI** \\ AND KHAIRUL SALEH*** \\ *Department of Mathematics, \\ King Fahd University of Petroleum and Minerals, \\ P.O. Box 5046, Dhahran 31261, Saudi Arabia. \\ Interdisciplinary Center of Smart Mobility and Logistics, \\ King Fahd University of Petroleum and Minerals, \\ P.O. Box 5067, Dhahran 31261, Saudi Arabia \\ E-mail: monther@kfupm.edu.sa \\ ** Department of Applied Mathematics and Sciences, \\ Khalifa University Abu Dhabi, UAE \\ E-mail: mohamed.khamsi@ku.ac.ae \\ *** Department of Mathematics, \\ King Fahd University of Petroleum and Minerals, \\ P.O. Box 5046, Dhahran 31261, Saudi Arabia. \\ E-mail: khairul@kfupm.edu.sa
}

\begin{abstract}
In this paper, we prove the existence of periodic points of asymptotically nonexpansive mappings defined on non-convex domains in uniformly convex Banach spaces. We also introduce the notion of firmly asymptotically nonexpansive mappings and prove the existence of fixed points of such mappings with non-convex domains.
\end{abstract}

Key Words and Phrases: Asymptotically nonexpansive mapping, fixed point, periodic point.

2020 Mathematics Subject Classification: 46B20, 47E10, 47H10.

\section{REFERENCES}

[1] M.R. Alfuraidan, M.A. Khamsi, A fixed point theorem for monotone asymptotic nonexpansive mapping, Proc. Amer. Math. Soc., 146(2018), 2451-2456.

[2] D. Ariza-Ruiz, L. Leustean, G. Lopez-Acedo, Firmly nonexpansive mappings in classes of geodesic spaces, Trans. Amer. Math. Soc., 366(2014), no. 8, 4299-4322.

[3] S.C. Bose, Weak convergence to the fixed point of an asymptotically nonexpansive map, Proc. Amer. Math. Soc., 68(1978), 305-308.

[4] F.E. Browder, W.V. Petryshyn, The solution by iteration of nonlinear functional equations in Banach spaces, Bull. Amer. Math. Soc., 72(1966), 571-575.

[5] K. Goebel, W.A. Kirk, A fixed point theorem for asymptotically nonexpansive mappings, Proc. Amer. Math. Soc., 35(1972), 171-174.

[6] Y.M. Hong, Y.Y. Huang, On $\lambda$-firmly nonexpansive mappings in non-convex sets, Bull. Inst. Math. Acad. Sinica, 21(1993), no. 1, 35-42. 
[7] W. Kaczor, Fixed points of $\lambda$-firmly nonexpansive mappings on non-convex sets, Nonlinear Anal., 47(2001), 2787-2792.

[8] B. Nanjaras, B. Panyanak, Demiclosed principle for asymptotically nonexpansive mappings in CAT spaces, Fixed Point Theory Appl., 2010(2010).

[9] G.B. Passty, Construction of fixed points for asymptotically nonexpansive mappings, Proc. Amer. Math. Soc., 84(1982), 213-216.

[10] J. Schu, Weak and strong convergence to fixed points of asymptotically nonexpansive mappings, Bull. Austral. Math. Soc., 43(1991), no. 1, 153-159.

[11] R. Smarzewski, On firmly nonexpansive mappings, Proc. Amer. Math. Soc., 113(1991), no. 3, 723-725.

[12] K.K. Tan, H.K. Xu, Fixed point iteration processes for asymptotically nonexpansive mappings, Proc. Amer. Math. Soc., 122(1994), 733-739.

[13] H.K. Xu, Existence and convergence for fixed points of mappings of asymptotically nonexpansive type, Nonlinear Anal.: Theory, Methods \& Applications, 12(16)(1991), 1139-1146.

[14] B.L. Xu, M.A. Noor, Fixed point iterations for asymptotically nonexpansive mappings in Banach spaces, J. Math. Anal. Appl., 267(2002), no. 2, 444-453.

Received: July 30, 2020; Accepted: October 22, 2020. 
